\title{
Levels of Personal Agency: Individual Variation in Action Identification
}

\author{
Robin R. Vallacher \\ Florida Atlantic University
}

\author{
Daniel M. Wegner \\ Trinity University
}

\begin{abstract}
This research examined individual differences in action identification level as measured by the $\mathrm{Be}$ havior Identification Form. Action identification theory holds that any action can be identified in many ways, ranging from low-level identities that specify how the action is performed to high-level identities that signify why or with what effect the action is performed. People who identify action at a uniformly lower or higher level across many action domains, then, may be characterized in terms of their standing on a broad personality dimension: level of personal agency. High-level agents think about their acts in encompassing terms that incorporate the motives and larger meanings of the action, whereas low-level agents think about their acts in terms of the details or means of action. Research on the convergent, divergent, and predictive validity of this construct examined its implications for the individual's overall competence in action, for the individual's inclination toward planful versus impulsive action and for the degree to which the individual's actions are organized by and reflected in the self-concept.
\end{abstract}

Some people think they can do big things. They set out to write a book, to make a fortune, or to win an election. There are others, however, who may undertake much the same tasks with far more meager aims in mind. They might get some ideas on paper, make a profit this week, or shake a few hands at the factory gate. Ultimately, the people who see their acts in big ways may find the same success as those who focus on the details. However, the two ways of identifying action are appropriate and effective in vastly different situations, and they promote radically distinct styles of action.

This research was designed to test the reliability and validity of an instrument assessing this action identification dimension. High levels of personal agency represent the tendency to understand one's action in terms of its consequences and implications, whereas low levels of personal agency represent the tendency to see one's action in terms of its details or mechanics. The dimension of personal agency level is derived from action identification theory, a set of principles on the understanding

The research reported in this article was supported in part by Grants BNS 78-26380 and BNS 86-06035 from the National Science Foundation. Preliminary reports of some aspects of the research were included in Vallacher and Wegner (1985).

We thank the following people for their valuable assistance in this research: Roya Ayman, Rebecca Bell, Joyce Cohen, Christie Cook, Pat Foster, John Gould, Jeffrey Kingree, Carol Marangoni, Kathy McCandless, Dean Mendoza, Lidian Pereira, Richard Sherman, Pilar Somoza, Kandy Stahl, Karen Walker, and Charles White. We also thank Roy Baumeister, James Pennebaker, William Swann, and five anonymous reviewers for their helpful comments on an earlier draft.

Correspondence concerning this article should be addressed to Robin R. Vallacher, Department of Psychology, Florida Atlantic University, Boca Raton, Florida 33431. and control of behavior (Vallacher \& Wegner, 1985, 1987; Wegner \& Vallacher, 1986). After briefly reviewing the theory, we show how the interplay of basic processes can give rise to reliable individual variation in personal agency level, and we then document empirically the consequences of such variation for action effectiveness, action planning, and self-conception.

\section{Action Identification Theory}

Any action can be identified in different ways, a point emphasized by many philosophers (e.g., Anscombe, 1957; Danto, 1963; Goldman, 1970; Ryle, 1949; Wittgenstein, 1953). The simple and seemingly unambiguous act of "drinking alcohol," for instance, could also be identified as "relieving tension," "rewarding oneself," "hurting oneself," "overcoming boredom," "getting drunk," or "swallowing" (Wegner, Vallacher, \& Dizadji, 1989). According to action identification theory, the identities for an action can be arrayed in a cognitive hierarchy, from low-level identities that specify how one acts to high-level identities that specify why or with what effect one acts. "Drinking alcohol" and "swallowing" for instance, have a hierarchical relation with each other in that the latter identity indicates how one does the former. Our research shows that there commonly are several levels in an act-identity hierarchy (Vallacher \& Wegner, 1985), so whether a particular act identity is considered high or low in level depends on the identity with which it is compared. Thus, although "drinking alcohol" is a higher-level identity with respect to "swallowing," it is a lower-level identity with respect to "getting drunk."

Despite the inherent uncertainty of action identification, people report knowing what they are doing and, when queried, tend to identify their action in a single way. The particular act identity that assumes prepotence for a person at a particular 
point in time reflects a trade-off between concerns for comprehensive understanding and effective performance of the action. A concern for comprehensive understanding leads people to identify their action in terms of its causal effects, socially conveyed meanings, self-evaluative implications, and other identities populating the highest levels in their identity hierarchy. This preference for relatively high-level identification is reflected in a key principle of the theory: When more than one identity is available to a person, there is a tendency to embrace the higherlevel identity (Wegner, Vallacher, Kiersted, \& Dizadji, 1986; Wegner, Vallacher, Macomber, Wood, \& Arps, 1984).

Because of their distance from the mechanics of action, however, high-level identities can be poor guides to action performance. An inexperienced squash player thinking only "win the game," for instance, may wind up playing a poor version of squash. According to another basic principle of the theory, then, when an action is performed poorly under a given identity, there is a tendency to adopt a lower-level identity for the act. The squash player who fails to "win the game" may begin to represent his or her action as simply "hitting the ball squarely." If the act still fails when identified in this way, the person may focus on yet lower-level identities (e.g., "watching the ball"). Our research shows that people move to lower-level identities when an action is difficult, unfamiliar, or complex (Vallacher, Wegner, \& Frederick, 1981; Wegner \& Vallacher, 1983), when their performance of the act is disrupted (e.g., Wegner et al., 1984, Experiment 2), or when they are given failure feedback on their performance (Vallacher, Wegner, \& Frederick, 1987).

Although representing opposing action identification tendencies, the two principles just described work in concert to promote adjustment in the control of action. This adjustment involves an oscillation over time between upward and downward movements in an identity hierarchy. When attempting an action, the person is naturally concerned with the larger effects and implications of the act, and so moves to higher-level identities available in the context or accessible in memory. Should the action prove difficult to maintain with these high-level identities in mind, however, the person moves to easier, lower-level identities. If these lower-level identities prove maintainable, the person becomes sensitive once again to higher-level identities, and so on, until a level of identification is established that matches the person's capacity to perform the action. Identities at a higher level than this optimum provide inadequate guides to action control, whereas those at a lower level promote an unnecessary disintegration of an action (Vallacher, Wegner, \& Somoza, 1989).

The interplay of these processes also provides for the emergence of new action. The potential for new action exists any time a person thinks about what he or she is doing in low-level terms and then is exposed to new high-level meanings of the behavior. If the high-level identity that is embraced differs notably from the high-level identity that set the action in motion, and if the person acts on the basis of this emergent identity, he or she may wind up doing something that has little similarity to his or her original action plan. Research to date confirms that disrupting people's action or otherwise inducing them to consider lower-level identities makes them susceptible to revised understanding of their behavior and can establish new courses of action (Wegner et al., 1984, 1986). Emergence of new action is unlikely to occur, meanwhile, if the person is able to maintain action at a high level.

In sum, level of action identification has two primary implications for the understanding and control of behavior. First, the level of an act's prepotent identity is indicative of the person's difficulty in maintaining the act; the more difficult the act, the lower the level at which it is likely to be identified. Second, identification level is integral to the emergence of action; anything that promotes relatively low-level identification establishes a crucial precondition for the acceptance of new comprehensive (high-level) understandings of the act and can change the nature of subsequent action.

\section{Levels of Personal Agency}

Reliable individual differences in level of action identification are clearly evident in specific action domains. As a rule, people vary in their degree of experience with a specific action, in their competence in its performance, and in the degree to which they have been exposed to information that allows them to understand the action's higher-level implications. These factors help to determine the individual's level of identification of that action, and because these factors may vary from action to action within the same individual, it is entirely possible for the individual to identify one action at a high level and another at a low level.

Against this backdrop of action-specific variation in identifcation level, we also find reliable individual variation in identification level across action domains. Early in our research in this area, we discovered a tendency for measures of identification level in one domain (e.g., "drinking alcohol") to show small but significant correlations with measures in seemingly disparate domains (e.g., "going to college"). It makes sense that action identification level might vary across people in this way. People differ in their capacities to perform the various basic actions that constitute all larger performances, and differ as well in the degree to which they can develop smooth and automatic actions that integrate rudimentary components. Because such capacities are implicated in all action, there may be reliable individual variation in identification level on the basis of overall variation in competence. At the same time, there are likely to be overall variations in the degree to which individuals encounter information that reminds them of the higher-level meanings of their actions. Some life situations may provide only an impoverished portrayal of the distal consequences of action (e.g., working on an assembly line), whereas others might yield more exposure to information about higher-level identities (e.g., working in the planning department).

It is thus possible to speak of individual differences in level of personal agency. At one extreme is the low-level agent, someone who operates on the world primarily at the level of detail. This person tends to approach an action with its mechanistic components in mind. At the other extreme is the high-level agent, someone who routinely views his or her action in terms of causal effects, social meanings, and self-descriptive implications. This person attempts to control action with respect to these consequence-defined identities. Although the person might have a stable, domain-specific identification level in familiar action domains, variation in level of personal agency will 
likely influence identification level across the many action domains with which the person has had less contact.

Levels of personal agency do not represent a trait in the most common sense of this term: a tendency to emit behaviors from within a content-defined class (e.g., "sociable" behaviors or "intelligent" behaviors) across a range of situations and consistently over time (G. W. Allport, 1966; Mischel, 1968). This traditional definition allows for a person's standing on a trait to be measured by accumulating trait-relevant behavioral instances over time and across situations, with more instances promoting a stronger inference that the person has the trait (Buss \& Craik, 1983; Epstein, 1979). The fundamental uncertainty of action identification calls into question the validity of any global attempts to classify behaviors into a priori trait categories (cf. Vallacher \& Wegner, 1987).

Because any act can be identified in many ways, it is unclear what criteria should be used to count acts toward particular behavioral traits. Suppose a person does something that can be described variously as "moving one's mouth," "uttering sounds," "speaking rapidly and loudly," "making reasonable points," "expressing an opinion," and "criticizing an acquaintance." What criterion should be used to select one of these identities, each representing a different level in the action's hierarchical organization, for accumulation toward the inference of a trait? Is the person a rapid speaker, an opinion expresser, a critic, or yet something else? Even if one could settle on a particular level of identification for counting acts, the fact that acts have multiple higher-level identities renders the classification of a given act into any one category essentially arbitrary. "Criticizing an acquaintance," for instance, could reasonably be counted as an instance of a trait such as unfriendly, but such a classification may miss entirely what the act meant to the actor. In criticizing the acquaintance, after all, the actor may have been "helping" or "demonstrating concern" for someone he or she cares about. On different occasions, moreover, the same lowerlevel act may reflect vastly different higher-level identities; criticizing an acquaintance might be a manifestation of unfriendliness at one time and a manifestation of interpersonal concern at another. Of course, there are some culturally general meanings that can be adduced, and this should allow the roughly reliable classification of some of the individual's acts in a way that would agree with the individual's own organization system. However, there is no guarantee that such counts will correspond with the meanings under which the actions arose, and confusion is thus inevitable.

These observations suggest that behavioral dispositions will inevitably fall short as vehicles for representing regularities in behavior. A more reasonable organizational scheme is given instead by the individual's own cognitive structure of action identifications. This hierarchical identity structure stretches from the substrate of lower-level identities to the highest-level identities the person is able to pursue, capturing between these extremes all the everyday actions that people admit to doing or intending. The height of this hierarchy is given by the individual's level of personal agency.

Viewed in this way, levels of personal agency go beyond assessing what behavioral dispositions a person has to address whether the person has traitlike dispositions at all. High-level agents are the only people who can be counted on to perform many of their behaviors with a view toward the more significant meanings of what they are doing. Low-level agents, in contrast, may often engage in actions that they never personally connect to larger meanings. In this sense, level of personal agency runs counter to the prevailing definition of personality as a collection of behavioral traits. Level of personal agency is an independent dimension that may distinguish just how much an individual has organized his or her actions into abstract, meaningful categories that can operate to channel behavior into dispositional tendencies.

\section{Overview}

When considered in light of the processes that promote variation in identification level, the personal agency construct holds implications for important aspects of personality. Three aspects in particular can be understood in terms of variation in levels of personal agency: action effectiveness, action planning, and self-conception. In the following sections, the link between personal agency level and each of these topics is considered conceptually and examined empirically.

\section{Method}

Subjects. A total of 1,404 subjects in 13 samples participated in this research. Ten samples (Samples 1-5 and 7-11) consisted of undergraduates at five universities who participated in exchange for extra credit in their psychology courses. Subjects in Sample 6 were faculty, staff, and employee volunteers at Trinity University; those in Sample 12 were gynecological outpatients who volunteered at a medical clinic in San Antonio, Texas; and those in Sample 13 were juvenile detainees at the Bexar County Department of Juvenile Probation in San Antonio. Each sample was administered the Behavior Identification Form (BIF), described later, to assess characteristic level of action identification, along with a subset of other measures. Table 1 shows each sample's source and size, and the sample mean and standard deviation on the BIF.

Measures. A total of 34 different measures were obtained for 1 or more of the 13 samples. They included 15 measures developed for this research, 16 standard assessment devices, and 3 archival behavior records. In the initial phase of this research, an instrument designed to assess individual differences in level of action identification was constructed. The relations between scores on this instrument and the other measures, both psychometric and behavioral, were then assessed in the various samples. Each measure was relevant to action effectiveness, action orientation, or self-understanding, or to a dimension conceptually independent of the personal agency construct. This allowed us to ascertain the convergent, predictive, and divergent validity of the level of personal agency construct.

\section{Behavior Identification Form}

Subjects in Sample 1 completed the BIF, an instrument designed to measure individual differences in level of personal agency. Each item on the BIF presents an act identity followed by two alternative identities, one lower and one higher in level; respondents are to choose the alternative that best describes the action for them. The exact instructions were as follows:

Any behavior can be identified in many ways. For example, one person might describe a behavior as "typing a paper," while another might describe the behavior as "pushing keys." Yet another person might describe the behavior as "expressing thoughts." We are interested in your personal preferences for how a number of different 
Table 1

Subject Sample Means and Standard Deviations

\begin{tabular}{|c|c|c|c|}
\hline \multirow[b]{2}{*}{ Sample source } & \multicolumn{3}{|c|}{$\begin{array}{l}\text { Behavioral Identification } \\
\text { Form }\end{array}$} \\
\hline & $n$ & $M$ & $S D$ \\
\hline \multicolumn{4}{|l|}{ 1. University of Texas at Austin } \\
\hline $\begin{array}{l}\text { 2. University of Texas at Austin } \\
\text { undergraduates }\end{array}$ & 100 & 16.24 & 5.20 \\
\hline $\begin{array}{l}\text { 3. University of Texas at Arlington } \\
\text { undergraduates }\end{array}$ & 285 & 15.87 & 5.36 \\
\hline 4. Trinity University & 200 & 10.07 & .50 \\
\hline undergraduates & 42 & 15.71 & 5.88 \\
\hline \multicolumn{3}{|l|}{ 5. Illinois Institute of Technology } & 5.60 \\
\hline $\begin{array}{l}\text { 6. Trinity University faculty, staff, } \\
\text { and employees }\end{array}$ & 110 & 14.98 & 5.82 \\
\hline 7. Illinois Institute of Technology & 98 & 15.63 & 5.48 \\
\hline $\begin{array}{l}\text { 8. Florida Atlantic University } \\
\text { undergraduates }\end{array}$ & 48 & 15.67 & 5.08 \\
\hline $\begin{array}{l}\text { 9. Florida Atlantic University } \\
\text { undergraduates }\end{array}$ & 95 & 15.61 & 5.07 \\
\hline \multicolumn{3}{|l|}{$\begin{array}{l}\text { 10. Florida Atlantic University } \\
\text { undergraduates }\end{array}$} & \\
\hline 11. Florida Atlantic University & 66 & 16.62 & 5.13 \\
\hline $\begin{array}{l}\text { 12. Medical Research Associates } \\
\text { (San Antonio) gynecological } \\
\text { outpatients }\end{array}$ & 59 & 15.72 & 5.02 \\
\hline \multicolumn{4}{|l|}{ 13. Bexar County Department of } \\
\hline Antonio) juvenile detainees & 125 & 15.43 & 5.32 \\
\hline
\end{tabular}

a This sample was collected independently by C. Marangoni.

b This sample was collected independently by $\mathbf{R}$. Ayman.

behaviors should be described. On the following pages you will find several different behaviors listed. After each behavior will be two choices of different ways in which the behavior might be identified. Here is an example:

\section{Attending class}

- a. sitting in a chair

-b. looking at the blackboard

Your task is to choose the identification, $a$ or $b$, that best describes the behavior for you. Simply place a check mark in the space beside the identification statement that you pick. Please mark only one alternative for each pair. Of course, there are no right or wrong answers. People simply differ in their preferences for the different behavior descriptions, and we are interested in your personal preferences. Be sure to mark your choice for each behavior. Remember, choose the description that you personally believe is more appropriate in each pair.

The alternative identities were derived from pilot subjects $(n=20)$, who were asked to provide as many redescriptions of each of the original identities as they could in a 10 -min period. The most frequently mentioned higher- and lower-level redescriptions for each original identity were used to construct the BIF.

The initial form of the BIF consisted of 60 items and was administered to the entire sample of 274 undergraduates (150 women, 124 men). Analysis of their responses indicated that a single dimension was being tapped (Cronbach's $\alpha=.84$ ). The item-total correlations for these items ranged from .05 to .45 with a mean of .25 . Using an item-total correlation of .27 as the criterion for item inclusion reduced the BIF to 25 items. Itemtotal correlations in this reduced scale ranged from .28 to .48 , and the internal consistency $(\alpha)$ of this scale was .85 . The 25 items of the final BIF are presented in Table 2.'

Subjects' level of personal agency was defined as the number of high-level alternatives chosen on the BIF. As revealed in Table 1 , mean scores on the BIF proved to be similar across the 13 samples. No sex differences in mean BIF scores were obtained in any of the samples. In subsequent research (Sample 4), level of personal agency measured in this way proved to be highly reliable over a 2 -week period, $r(42)=.91$. The BIF thus provides an internally consistent and temporally stable means of assessing individual differences in level of identification across an array of actions.

\section{Levels of Agency and Action Effectiveness}

Our suspicions concerning individual differences in level of action identification are predicated on the assumption that people differ reliably from one another in their overall action competence. Low-level agents presumably can claim true expertise in relatively few action domains and must conduct their behavior with conscious attention to detail. High-level agents, in contrast, may well have achieved expertise in many action domains and can maintain their action with higher-level identities in mind.

This reasoning leads to several predictions, each of which is tested in the present research. First, compared with high-level agents, low-level agents should judge various everyday actions as more difficult. In prior research, we have found an association between the level at which particular actions are identified and various indicators of that action's difficulty (Vallacher \& Wegner, 1987). Thus, actions tend to be identified at a relatively low level to the extent that they are difficult, complex, unfamiliar, require a long time to enact, and take long to learn. If this general tendency has an individual-difference counterpart, lowlevel agents should consider a wide assortment of actions to be more difficult, complex, and so on than should higher-level agents.

This reasoning also suggests that low-level agents should be more prone than high-level agents to chronic disruption in their

\footnotetext{
' We performed a factor analysis to assess the possibility that the BIF tapped action identification tendencies specific to subsets of items. A principal-axis solution revealed the existence of one primary factor with an eigenvalue of 5.65 , with four minor factors (eigenvalue range $=2.04$ 1.05). A varimax rotation failed to provide an alternative solution in 24 iterations, suggesting that the BIF is indeed a unidimensional scale. The observation that 19 of the 25 items had their highest loadings on the primary factor and that the remaining items had positive loadings on this factor as well (range $=0.15-0.30$ ) substantiates this conclusion. The finding that 6 items did load more heavily on minor factors, however, serves as a reminder that certain actions can have sources of identitylevel variance that depart from a unitary individual-difference dimension (Vallacher \& Wegner, 1987).
} 
Table 2

The Behavior Identification Form

\begin{tabular}{|c|c|c|c|c|c|}
\hline Item & $M$ & $\begin{array}{c}\text { Item-total } \\
r \\
\end{array}$ & Item & $M$ & $\begin{array}{c}\text { Item-total } \\
r\end{array}$ \\
\hline $\begin{array}{l}\text { 1. Making a list } \\
\text { a. Geting organized } \\
\text { b. Writing things down }\end{array}$ & 0.73 & .30 & $\begin{array}{l}\text { 14. Climbing a tree } \\
\text { a. Getting a good view } \\
\text { b. Holding on to branches }\end{array}$ & 0.40 & .37 \\
\hline $\begin{array}{l}\text { 2. Reading } \\
\text { a. Following lines of print } \\
\text { b. Gaining knowledge } \mathrm{e}^{\mathrm{a}}\end{array}$ & 0.87 & .29 & $\begin{array}{l}\text { 15. Filling out a personality test } \\
\text { a. Answering questions } \\
\text { b. Revealing what you're like }\end{array}$ & 0.69 & .31 \\
\hline $\begin{array}{l}\text { 3. Joining the Army } \\
\text { a. Helping the Nation's defense } \\
\text { b. Signing up }\end{array}$ & 0.47 & .39 & $\begin{array}{l}\text { 16. Toothbrushing } \\
\text { a. Preventing tooth decay } \\
\text { b. Moving a brush around in one's mouth }\end{array}$ & 0.79 & .41 \\
\hline $\begin{array}{l}\text { 4. Washing clothes } \\
\text { a. Removing odors from clothes } \\
\text { b. Putting clothes into the machine }\end{array}$ & 0.57 & .34 & $\begin{array}{l}\text { 17. Taking a test } \\
\text { a. Answering questions } \\
\text { b. Showing one's knowledge }{ }^{a}\end{array}$ & 0.53 & .35 \\
\hline $\begin{array}{l}\text { 5. Picking an apple } \\
\text { a. Getting something to eat }{ }^{\mathrm{a}} \\
\text { b. Pulling an apple off a branch }\end{array}$ & 0.62 & .31 & $\begin{array}{l}\text { 18. Greeting someone } \\
\text { a. Saying hello } \\
\text { b. Showing friendliness }\end{array}$ & 0.74 & .35 \\
\hline $\begin{array}{l}\text { 6. Chopping down a tree } \\
\text { a. Wielding an axe } \\
\text { b. Getting firewood }\end{array}$ & 0.61 & .33 & $\begin{array}{l}\text { 19. Resisting temptation } \\
\text { a. Saying "no" } \\
\text { b. Showing moral courage }{ }^{a}\end{array}$ & 0.48 & .34 \\
\hline $\begin{array}{l}\text { 7. Measuring a room for carpeting } \\
\text { a. Getting ready to remodel } \\
\text { b. Using a yardstick }\end{array}$ & 0.70 & .38 & $\begin{array}{l}\text { 20. Eating } \\
\text { a. Getting nutrition } \\
\text { b. Chewing and swallowing }\end{array}$ & 0.59 & .43 \\
\hline $\begin{array}{l}\text { 8. Cleaning the house } \\
\text { a. Showing one's cleanliness }{ }^{a} \\
\text { b. Vacuuming the floor }\end{array}$ & 0.60 & .37 & $\begin{array}{l}\text { 21. Growing a garden } \\
\text { a. Planting seeds } \\
\text { b. Getting fresh vegetables }\end{array}$ & 0.65 & .32 \\
\hline $\begin{array}{l}\text { 9. Painting a room } \\
\text { a. Applying brush strokes } \\
\text { b. Making the room look fresh }\end{array}$ & 0.65 & .41 & $\begin{array}{l}\text { 22. Traveling by car } \\
\text { a. Following a map } \\
\text { b. Seeing countryside }\end{array}$ & 0.78 & .30 \\
\hline $\begin{array}{l}\text { 10. Paying the rent } \\
\text { a. Maintaining a place to live }{ }^{\mathrm{a}} \\
\text { b. Writing a check }\end{array}$ & 0.65 & .48 & $\begin{array}{l}\text { 23. Having a cavity filled } \\
\text { a. Protecting your teeth } \\
\text { b. Going to the dentist }\end{array}$ & 0.47 & .41 \\
\hline $\begin{array}{l}\text { 11. Caring for houseplants } \\
\text { a. Watering plants } \\
\text { b. Making the room look nice }\end{array}$ & 0.40 & .35 & $\begin{array}{l}\text { 24. Talking to a child } \\
\text { a. Teaching a child something } \\
\text { b. Using simple words }\end{array}$ & 0.66 & .32 \\
\hline $\begin{array}{l}\text { 12. Locking a door } \\
\text { a. Putting a key in the lock } \\
\text { b. Securing the house } \mathrm{a}^{\mathrm{a}}\end{array}$ & 0.89 & .31 & $\begin{array}{l}\text { 25. Pushing a doorbell } \\
\text { a. Moving a finger } \\
\text { b. Seeing if someone's home }{ }^{\mathrm{a}}\end{array}$ & 0.92 & .28 \\
\hline $\begin{array}{l}\text { 13. Voting } \\
\text { a. Influencing the election } \\
\text { b. Marking a ballot }\end{array}$ & 0.66 & .34 & & & \\
\hline
\end{tabular}

Note. $M$ is proportion of higher-level responses.

${ }^{\text {a }}$ Higher-level alternative.

everyday actions. Disruptions of this kind, commonly called absent-minded errors or action slips (e.g., Broadbent, Cooper Fitzgerald, \& Parkes, 1982; Norman, 1981; Reason \& Mycielska, 1982), tend to occur most often when a person is doing a routine action in a highly familiar setting. For example, one might forget why one went from one part of the house to another. Action identification theory holds that routine, familiar actions are best maintained with respect to relatively high-level identities, so the proclivity to undertake action at low level is likely to prove nonoptimal in these contexts (e.g., Vallacher et al., 1989). We would thus expect a greater incidence of action slips among lower- than among higher-level agents.

The link between level of agency and action effectiveness should also be manifest in the number of skilled actions in the respective repertoires of low- and high-level agents. High-level agents are likely to have experience with a wider array of skilled activities than are low-level agents, and they should claim greater proficiency at these activities as well. By the same logic, high-level agents are likely to have more hobbies than are lowlevel agents.

\section{Measures}

One standard measure and eight measures designed for this research assessed action effectiveness. Subjects in Sample 2 completed the Cognitive Failures Questionnaire (CFQ), a scale developed by Broadbent et al. (1982) to assess self-reported proclivity for making various kinds of action errors in everyday life. Respondents rated (on 4-point scales) how often in the past 6 months they had done each of 25 "absent-minded" actions. Examples include dropping things, forgetting why one went from one part of the house to another, bumping into people, and accidentally throwing away the thing one wants and keeping what one meant to throw away. The CFQ has satisfactory internal 
Table 3

Levels of Personal Agency and Action Effectiveness

\begin{tabular}{lccc}
\hline \multicolumn{1}{c}{ Measure } & Sample & $n$ & $r$ \\
\hline Action failure & 2 & 100 & $-.24^{* *}$ \\
Action proficiency & 11 & 38 & $.31^{*}$ \\
Hobbies & 11 & 38 & .13 \\
Hobby time & 11 & 38 & $.27^{*}$ \\
Maintenance indicators & & & \\
$\quad$ Action difficulty & 11 & 66 & $-.22^{*}$ \\
Action familiarity & 11 & 66 & $.24^{*}$ \\
Action complexity & 11 & 66 & .05 \\
Enactment time & 11 & 66 & -.04 \\
Learning time & 11 & 66 & -.09 \\
\hline
\end{tabular}

${ }^{*} p<.05 . \quad * * p<.02$.

consistency ( $\alpha=.79$ ), high test-retest reliability- $r(57)=.82$ over 21 weeks, $r(32)=.80$ over 65 weeks-and shows an encouraging pattern of correlations with theoretically relevant measures (e.g., observer ratings of absent-mindedness, lack of concentration, and clumsiness).

Part of Sample $11(n=38)$ completed a questionnaire we constructed to tap action proficiency. For each of 50 actions, subjects were asked if they had attempted it, and if so, how well they could do it relative to other people who perform the action. Examples include playing a musical instrument, teaching tricks to a pet, planning a party, typing, and building furniture. Scores for each act were no attempt (0), and poor (1), average (2), or good (3) performance relative to others. The mean for the 50 actions was the measure of action proficiency. Subjects were also asked to list the number of hobbies they had and how long they had been involved with each one.

Subjects in Sample 11 completed an instrument used by Wegner and Vallacher (1983; see Vallacher \& Wegner, 1987) to determine the maintenance difficulty of the 25 actions (item stems) on the BIF. Subjects rated each action on five dimensions: difficulty, familiarity, complexity (number of subacts), enactment time, and learning time (time it takes to learn to do the action well). Each dimension was used to rate each action on a 5-point scale with the appropriate endpoints (e.g., not difficult to very difficult). The ratings across the 25 actions formed reliable scales for each dimension (mean $\alpha=.84$ ). Each subject was assigned a score for action difficulty, action familiarity, action complexity, enactment time, and learning time.

\section{Results}

Table 3 shows that scores on the BIF were often reliably associated with action effectiveness. Thus, low-level agents reported a greater tendency to make action errors than did their highlevel counterparts. ${ }^{2}$ High-level agents, in turn, reported greater proficiency at a variety of skilled actions than did low-level agents, and also reported greater involvement in hobbies. The ratings of the actions from the BIF also showed the expected trend, but only in two of five cases. High-level agents rated the actions as less difficult and more familiar than did low-level agents, but no differences arose for judgments of action complexity, enactment time, or learning time.

\section{Levels of Agency and Action Planning}

A common denominator of many dimensions of personality is the distinction between personal planning and environmental control of action. Thus, people are said to have either an internal or external locus of control (Rotter, 1966), to act either in accord with personal standards or the cues provided by others (Snyder \& Campbell, 1982), to plan behavior or act on impulse (Kipnis, 1971), to be self-motivated or falter when reinforcement is absent (Dishman \& Ickes, 1981), or to behave consistently or inconsistently across time and situations (Campus, 1974). These distinctions may involve the action premeditation that varies with differing levels of personal agency.

High-level identification shields people against the emergence of alternative identities that could alter the course of action. Whether one appears responsive to situational cues and constraints, therefore, or instead maintains a personal plan of action despite these potential controlling influences depends on one's level of personal agency. People with a high-level understanding already know what they are doing and so are less primed to accept other understandings (at the same level) that are provided by the context of the action. Because they often lack a high-level theme to integrate what they do, low-level agents look to information provided in the action's context to determine what they are doing or should be attempting to do. Subtle changes in contextual cues are thus readily noticed and give emergent meaning to their action. However, because new high-level identities may be difficult to enact, these episodes of

\footnotetext{
${ }^{2}$ Despite the relatively high internal consistency of the CFQ, a factor analysis (principal axis rotated to a varimax solution) revealed the existence of five independent domains of cognitive failure: goal attainmentcompletion (Do you read something and find you haven't been thinking about it and must read it again? Do you find you forget whether you've turned off a light or a fire or locked the door? Do you have trouble making up your mind? Do you find you can't quite remember something although it's "on the tip of your tongue"? Do you find you can't think of anything to say?); unintended consequences (Do you bump into people? Do you say something and realize afterwards that it might be taken as insulting? Do you find yourself suddenly wondering whether you've used a word correctly? Do you find you accidentally throw away the thing you want and keep what you meant to throw away-as in the example of throwing away the matchbox and putting the used match in your pocket? Do you drop things?); attention to detail (Do you fail to notice signposts on the road? Do you fail to listen to people's names when you are meeting them? Do you leave important letters unanswered for days? Do you find you forget people's names?) memory for detail (Do you find you forget which way to turn on a road you know well but rarely use? Do you forget where you put something like a newspaper or a book? Do you daydream when you ought to be listening to something? Do you find you forget what you came to the shops to buy?); and distraction (Do you find you forget why you went from one part of the house to the other? Do you find you forget appointments?) Correlational analyses $(n=100)$ revealed that low-level agents experience more failures than high-level agents with respect to goal attainment-completion $(r=-.20, p<.04)$, unintended consequences $(r=-.21, p<.04)$, and distraction $(r=-.20, p<.04)$, but not with respect to attention to detail and memory for detail. Indeed, it could reasonably be argued that these latter dimensions of cognitive failure should be more prevalent among high-level as opposed to lower-level agents, in that they seem to confer advantage on low-level action control.
} 
emergence are often short-lived. The failure of action at a high level then moves low-level agents back to a lower level, preparing them to emerge with yet another unplanned high-level theme. Overall, then, low-level agents might engage in impulsive as opposed to planned behavior, responding to cues and pressures salient in the situation, whereas higher-level agents might show greater stability in their actions across contextual variations.

The link from levels of agency to action planning also suggests clear behavioral predictions in the area of susceptibility to crime opportunities (Wegner \& Vallacher, 1986). Levels of personal agency may influence tendencies to engage in impulsive, opportunistic, criminal behavior. The low-level agent is ripe for such action, ready to emerge with new acts shaped by the context of the moment. This person would be unlikely to appreciate the more subtle, higher-level qualities of an attractive action, moral implications included, and so might act in a brash, seemingly thoughtless manner. (The same lack of planning might lead low-level individuals to perform impromptu courageous acts at times as well.) The high-level agent would already have a plan in situations that invite impulse, however, and so would be relatively less likely to succumb. High-level agents would also be alert to the moral consequences of their actions, and unless they had chosen a criminal career, would be sufficiently aware of what they were doing to avoid acts with potentially undesirable meanings. So, beyond considering the influence of personal agency on standard measures of action planning, we included in this research a specific test of their influence on criminal behavior.

\section{Measures}

The measures of planning included three established scales (self-motivation, locus of control, and self-monitoring), two measures designed for this work, and three forms of behavioral observation. Subjects in Sample 3 completed a self-report measure of self-motivation (Dishman \& Ickes, 1981), the tendency to persevere in a course of action independent of situational cues and reinforcements that favor other courses of action. The 40-item scale calls for a 5-point self-rating on each item (e.g., "I like to set goals and work toward them," "I can persevere at stressful tasks even when they are physically tiring or painful"). Subjects in three samples (1, 7, and 10) completed Snyder's (1974) Self-Monitoring scale, a measure of the tendency to respond to internal frames (low self-monitoring) versus situational cues of appropriate behavior (high self-monitoring). Subjects in three samples (1, 7, and 12) completed Rotter's (1966) Locus of Control scale. A scale designed for this research, completed by subjects in Sample 4, measured self-reported impulsiveness. The 10 items constituting this measure $(\alpha=.79)$ were designed to tap impulsiveness as defined by Kipnis (1971). Examples include "I do things on impulse," "I rarely do things the same way twice," and "If something more exciting comes along, I typically will skip class."

A diary measure of self-reported action instability was also developed. Subjects in Sample 4 were asked to keep a record of their behavior over a 2-day period and to do so again 2 weeks later. They were provided with a list of 18 classes of activities; these were generated by 15 pilot subjects asked to "list the vari- ous things that a college student does in his or her daily life." The activity classes reflected relatively high-level identities (e.g., cultural activities) that subsumed more specific actions (theatre, movies, concerts, etc.). For consecutive half-hour time segments spanning a 2-day period, subjects were to indicate what they were doing by writing in a code designating the activity. This reporting was to be done at the end of each day, before going to bed. For each activity, the difference in the number of half-hour segments indicated at the first and second administration was squared. A subject who indicated that she spent $6 \mathrm{hr}$ studying in the first 2-day period but only $2 \mathrm{hr}$ studying in the second 2-day period, for instance, would get a score of 64 for that activity. These values were then summed across the 18 activity classes to yield a measure of action instability for each subject. A high score on this measure reflects the tendency to change the amount of time devoted to particular classes of action.

The final assessment of action planning was in the area of criminal behavior, and was accomplished with behavioral records taken for Sample 13, the juvenile detainees. The offense records of these subjects were reviewed, as were the school status records (i.e., unenrolled, enrolled, suspended, or expelled) and family status records (i.e., intact vs. single-parent or guardian home). Recorded offenses included homicide, rape, robbery, assault, aggravated assault, use of controlled substances, use of toxic inhalants, alcohol use, public intoxication, trespassing, criminal mischief, burglary, theft, truancy, violation of parole, and running away from home. Overall measures were derived to include school trouble (suspension or expulsion), intact family (intact vs. other), and total number of offenses.

\section{Results}

Level of personal agency reliably influenced several measures of action planning (see Table 4). Compared with high-level agents, low-level agents reported greater impulsiveness and less temporal stability in their behavior, and their lower self-motivation suggests they are less persistent in their behavior when faced with competing goals made salient by the action context. Low-level agents tended to report more self-monitoring than did high-level agents, although this relation was significant in only one of the three samples. Also, in three samples, high-level agents scored as more internal in locus of control than did lowlevel agents. Thus, the tendency to identify what one does in high-level terms is associated with the feeling that the larger effects of one's behavior are within one's personal control.

The results for juvenile detainees (Sample 13) extend this view of personal agency and action planning. A majority of these subjects had been detained for some offense, and level of personal agency was predictive of this. High-level agents were less likely to have an offense record, $r(125)=-.17, p<.05$, indicating that in a broad sense, they were able to forestall at least one long-term negative consequence of their behavior. Consistent with this interpretation is the finding that high-level agents were also less likely to experience school trouble, $r(125)=-.17, p<.05$. It is notable, finally, that high-level agents more often had intact family settings, $r(125)=.16, p<$ .05 . There may be some developmental connection between the 
Table 4

Levels of Personal Agency and Action Orientation

\begin{tabular}{lccc}
\hline \multicolumn{1}{c}{ Measure } & Sample & $n$ & $r$ \\
\hline Self-motivation & 3 & 285 & $.30^{* * *}$ \\
Self-monitoring & & & \\
$\quad$ Sample 1 & 1 & 126 & -.11 \\
Sample 2 & 7 & 97 & -.12 \\
Sample 3 & 10 & 38 & $-.29^{*}$ \\
Impulsiveness & 4 & 40 & $-.31^{*}$ \\
Action instability & 4 & 42 & $-.26^{*}$ \\
Internal-external control & & & \\
$\quad$ Sample 1 & 1 & 133 & $-.23^{* *}$ \\
Sample 2 & 7 & 97 & $-.23^{*}$ \\
Sample 3 & 12 & 59 & $-.38^{* *}$ \\
\hline
\end{tabular}

$* p<.05 .^{* *} p<.005 . \quad{ }^{* * *} p<.001$.

stability of the family and the degree to which children can anticipate the consequences of what they do.

\section{Levels of Agency and Self-Conception}

To know what one is like is to know what one has done, is doing, or is inclined to do. When stated in such terms, the self-defining potential of action is hardly controversial. It is important to recognize, however, that self-conception is not an inevitable by-product of action identification. Indeed, the self-defining potential of action only becomes apparent when one's action is understood at a relatively high level. One may look on one's actions in a given day as nothing more than "driving," "cooking," and "getting dressed," for example. Although such identities are sufficient to perform these actions, they hardly carry a great deal of significance for self-understanding (cf. Anderson \& Ross, 1984). They reveal little more than that one is a driver, a cook, and not a nudist. However, these same actions might also be identifiable, respectively, as "breaking a traffic law," "preparing a gourmet meal," and "trying to look nice for a lover." These higher-level identities give more information about the person behind the action. Even more explicit depictions of the self might arise if yet higher-level act identities were known, for example, "being criminal," "being creative," and "being lovable." Although lower-level identities may hold little significance, higher-level identities can provide meaningful portrayals of the self.

It is not surprising, then, that assessment of people's self-conceptions typically involves self-ratings along relatively highlevel action dimensions reflective of behavioral propensities. In this research tradition, people are assumed to think of themselves in terms of such traits as cooperative versus competitive, extraverted versus introverted, and selfish versus altruistic (Wylie, 1979). Although traits need not always represent the highest level of identification available for any action, they provide broad equivalence classes or categories for a variety of lowerlevel identities. The superordinate nature of traits, as well as their discriminability from one another, has led some researchers to argue that traits provide a basic level of categorization in person understanding (Cantor \& Mischel, 1979).

It may be a mistake to assume, however, that everyone attains unambiguous self-understanding with respect to traitlike act identities. In fact, low-level agents may only infrequently derive meaningful self-understanding from what they do. Because they are consciously concerned with the minutiae of action, they are likely to think about the self in a relatively impoverished way: as the author of simple movements. High-level agents, in turn, tend to conceptualize most of their actions in more meaningful terms, and these high-level identities often capture important traitlike themes of self-conception. Compared with low-level agents, then, higher-level agents are more likely to have a clear and stable sense of what they are like with respect to abstract trait dimensions. Past research has addressed whether particular traits are relevant to self-understanding for particular people (e.g., D. J. Bem \& Allen, 1974; Markus, 1977). The present perspective goes on to suggest that traits may be generally relevant or irrelevant for self-understanding.

The measurable differences in self-understanding between low- and high-level agents should be several. First, when asked to describe themselves on trait dimensions (e.g., cooperative vs. competitive), low-level agents should express less overall certainty than their higher-level counterparts. Low-level agents should also attach less overall importance to traits for self-understanding than should high-level agents. When asked to indicate the sorts of things that come to mind when thinking about themselves, low-level agents should spontaneously generate selfdescriptors that are less traitlike than those generated by higherlevel agents. Finally, because low-level agents have little sense of what they are like with respect to abstract dispositions, they should be acutely sensitive to the feedback provided by others concerning such dispositions. By way of contrast, because highlevel agents have a clear and stable high-level understanding of what their actions signify, they should be relatively impervious to socially provided feedback concerning their standing on trait dimensions.

\section{Measures}

Five measures were developed to tap aspects of self-understanding, and three of these were completed by Sample 1. One measure, based on earlier work (Vallacher, 1975; Vallacher, Bennett, \& Swann, 1982), assessed subjects' certainty regarding their standing on various trait dimensions. It consisted of 20 bipolar trait scales (e.g., generous-stingy, independent-conforming, friendly-reserved). Subjects rated how certain they were of what they are like with respect to each trait dimension on 9-point response scales. Seventeen of the 20 items had an item-total correlation greater than .34 and formed an internally consistent scale $(\alpha=.85)$. Responses to these items were summed to yield a measure of self-certainty.

A portion of Sample $1(n=127)$ rated the same 20 traits in a different way (cf. Vallacher, 1975; Vallacher et al., 1982). Subjects were to indicate the extent to which they typically thought of themselves in terms of each trait. The instructions suggested that perhaps not all traits are equally important for self-definition; some traits may provide typical ways of thinking about and evaluating oneself, whereas others may rarely be considered at all in relation to oneself. Subjects used 9-point response scales, anchored by very important and not at all important, for these judgments. All items had an item-total correlation greater than 
.58 , and responses to them were averaged to yield a measure of trait importance $(\alpha=.89)$.

The same subsample also rated themselves on the 20 traits as a measure of overall self-evaluation. Subjects indicated on 9point scales how they viewed themselves with respect to each dimension. As these traits all have an evaluative tone, a measure of self-evaluation was derived by averaging positive self-ratings across the 20 traits. This measure was internally consistent ( $\alpha=$ .94 ), with a minimum item-total correlation of .30 .

Subjects in Sample 10 were asked to list the personal qualities or characteristics that came to mind when they thought about themselves. They were asked to list as many features that provided ways of thinking about themselves as they could in a 10min period. Two judges independently rated the identification level of each feature using a 3-point scale, with 1 as low level (e.g., facial expressions, gestures), 2 as intermediate level (e.g., talkative, attentive), and 3 as high level (e.g., sincerity, sociability). The raters agreed $94 \%$ of the time; in disagreements, they discussed the feature until they reached consensus. The mean identification level across subjects' feature lists was considered a measure of their construct level.

A final measure was used in a study by Wegner et al. (1986, Experiment 2) to assess subjects' acceptance of bogus personality feedback (Sample 5). As input for this feedback, subjects were asked to describe their acts in a recent interaction in either low-level terms (e.g., specific comments and gestures) or highlevel terms (e.g., opinions expressed, values demonstrated). A computer program ostensibly processed these descriptions and then provided feedback indicating that the subject was either more cooperative or more competitive than most people. After examining the feedback, subjects rated on 9-point scales how accurate they felt the feedback was, whether they agreed with the computer program's assessment of their personality, and whether they felt the program was a valid way of assessing personality. The three items were intercorrelated (mean interitem $r=.63$ ), so they were averaged to yield a measure of feedback acceptance. This measure reflects how malleable subjects' selfconcepts are in the face of social feedback.

\section{Results}

The correlations between BIF scores and the self-measures, presented in Table 5, are in accord with the expected connection between personal agency and self-understanding. Low-level agents indicated less overall certainty in their standing on trait dimensions than did high-level agents, and they judged traits to be less relevant to their self-views as well. The significant correlation between BIF scores and construct level confirms that lowlevel agents tend not to think about themselves in traitlike terms, but rather in terms of low-level characteristics such as mannerisms and style.

Results also revealed that scores on the BIF were negatively related to the acceptance of feedback about the self. Apparently, high-level agents in the Wegner et al. (1986) study already knew what their action signified about them, and this sense of self enabled them to resist new high-level action identities (cooperativeness or competitiveness) given in the bogus feedback. Lowlevel agents, on the other hand, had a less well-anchored sense of their traits and so were receptive to the high-level, traitlike
Table 5

Levels of Personal Agency and Self-Understanding

\begin{tabular}{lccc}
\hline \multicolumn{1}{c}{ Measure } & Sample & $n$ & $r$ \\
\hline Self-certainty & 1 & 270 & $.17^{* *}$ \\
Trait importance & 1 & 126 & $.23^{* *}$ \\
Self-evaluation & 1 & 127 & -.01 \\
Construct level & 10 & 23 & $.60^{* * *}$ \\
Feedback acceptance & 5 & 49 & $-.27^{*}$ \\
\hline
\end{tabular}

${ }^{*} p<.03 . \quad{ }^{* *} p<.005 . \quad{ }^{* * *} p<.001$.

identities provided in the feedback. ${ }^{3}$ The results also revealed that level of agency was not reliably correlated with self-evaluation. Thus, the relevance of personal agency to the certainty and malleability of self-understanding does not appear to be mediated by the positivity of one's self-view.

\section{Divergent Validity}

Thirteen standard measures were included for the purpose of assessing divergent validity. The particular measures were selected because they tap dimensions that can be distinguished theoretically from level of personal agency on one of two bases. First, dimensions were chosen that diverge from level of agency in terms of their content domain. Divergence from these would indicate the independence of agency from other dimensions that might only share similar assessment methods. Second, dimensions were chosen to represent traits that might be considered more general than level of personal agency. Divergence from dimensions such as intelligence and cognitive style would indicate the specific relevance of personal agency to action rather than to mental functioning generally.

\section{Measures}

Six of the measures tap various aspects of cognitive style and ability: the Otis Self-Administering Tests of Mental Ability (Otis, 1956), a group-administered IQ test (Sample 8); the Concealed Figures Test (Thurstone, 1944), a test of field independence (Witkin, Dyk, Faterson, Goodenough, \& Karp, 1962; Sample 8); category width (Pettigrew, 1958; Sample 9); tolerance for ambiguity (MacDonald, 1970; Sample 9); dogmatism (Rokeach, 1960; Sample 9); and the Role Construct Repertory Test (Bieri et al., 1966), a measure of cognitive complexity based on Kelly's (1955) personal construct theory (Sample 9). Subjects also completed the Self-Consciousness scale (Fenigstein, Scheier, \& Buss, 1975), from which separate private and public self-consciousness scores were derived (Sample 2); Kohlberg's moral reasoning interviews (Colby et al., 1978), from which a moral maturity score was derived (Sample 6); the Jenkins Activity Survey (Form T; Krantz, Glass, \& Snyder, 1974), which assesses Type A personality (Sample 7); S. L. Bem's (1974) Sex-Role Inventory, from which Feminine and Mascu-

\footnotetext{
${ }^{3}$ This tendency was manifest in both feedback conditions and in both manipulated identification-level conditions, as none of the correlations (range $=-.18$ to -.34 ) departed significantly from the overall value.
} 
Table 6

Levels of Personal Agency and Various Personality Measures

\begin{tabular}{lccr}
\hline \multicolumn{1}{c}{ Measure } & Sample & $n$ & $r$ \\
\hline IQ & 8 & 48 & -.12 \\
Field independence & 8 & 48 & -.13 \\
Category width & 9 & 85 & -.11 \\
Tolerance for ambiguity & 9 & 82 & .10 \\
Dogmatism & 9 & 86 & .00 \\
Cognitive complexity & 9 & 67 & .17 \\
Moral maturity score & 6 & 110 & .07 \\
Private self-consciousness & 2 & 100 & .13 \\
Public self-consciousness & 2 & 100 & -.06 \\
Masculinity & 7 & 95 & .10 \\
Femininity & 7 & 95 & -.09 \\
Least Preferred Co-Worker Scale & 7 & 97 & .00 \\
Type A & 7 & 98 & .07 \\
\hline
\end{tabular}

line scores were derived (Sample 7); and the Least Preferred CoWorker Scale (LPC; Fiedler \& Chemers, 1984), a measure of social versus task orientation (Sample 7). We expected that the BIF would exhibit little relation with any of these measures.

\section{Results}

None of the measures included for purposes of establishing divergent validity were reliably correlated with level of personal agency (see Table 6). Thus, the BIF is not a measure of mental ability (IQ, field independence), and although it clearly is a cognitive measure, it taps a style of thinking that is distinct from other cognitive styles (category width, tolerance for ambiguity, dogmatism, cognitive complexity, moral maturity). The BIF is unrelated to self-consciousness; although the correlation with private self-consciousness is marginally reliable $(p<.10)$, it does not warrant the inference that personal agency enhances self-attention. The BIF is also orthogonal to social versus task orientation (LPC), gender identity (masculinity, femininity), and coronary-prone behavior pattern (Type A). It appears, then, that although level of agency does covary with a constellation of theoretically related phenomena, it is a feature of personality that is distinct from many other traits that do not fit into this theoretical frame.

\section{Discussion}

Levels of personal agency represent very different ways in which mind can impinge on what people do. We first consider what these results indicate about the opposing personalities of high- and low-level agents, and then reflect on the repercussions of this distinction for inquiry into personality more generally.

\section{The How People and the Why People}

Levels of personal agency partition people according to two extremes-those more likely to think about how they act, and those more inclined to identify why they act. Low-level agents are the "how" people, and it makes sense that they think this way. After all, they are more prone to disruption in their everyday behavior and tend to have less proficiency at actions involving some degree of skill. The low-level agent can be looked on as a chronic klutz, someone who commonly makes action errors and so must keep focusing on the details of action in order to negotiate the difficult path toward effective action performance. $\mathrm{He}$ or she is thus always "taking a step" or "moving a finger" or "looking both ways."

From this mechanical vantage point, the how person is quite ready to accept new possible directions for behavior. The lowlevel agent is sensitive to contextual cues for purposes of action guidance. Low-level agents were found to be more impulsive, less self-motivated, less consistent in their behavior over time, and more external in their locus of control than were their higher-level counterparts. In short, low-level agents' conscious concern with action details, necessitated by their relative ineffectiveness, primes them for repeated episodes of emergence whenever they are exposed to new action possibilities.

High-level agents' conscious concern with an action's significance-made possible by their relative effectivenessshields them against such emergence, enabling them to maintain a personally chosen course of action in the face of new action meanings afforded by the action context. They are the "why" people, the individuals who preconceive their actions in terms of distal consequences and implications. This allows a consistency and stability in action that escapes the how person. The tendency to understand why one is acting allows a unique sensitivity to the moral implications of actions as well, and compared with low-level agents, high-level agents are less inclined to commit opportunistic criminal offenses.

Finally, low- and high-level agents differ in their respective forms of self-understanding. Low-level agents have little sense of what they are like with respect to abstract behavioral propensities (i.e., personality traits), defining themselves instead in terms of how they do things. They are uncertain about their traits and, indeed, view traits as unimportant to their self-views. Of course, this low-level orientation makes them easy marks for those who might provide them with false information regarding their abstract personality characteristics. In contrast, high-level agents have an abstract sense of what their actions mean, and so are relatively impervious to socially provided generalizations concerning their behavioral dispositions. Their overall self-estimates may not be any more positive than those of low-level agents, but they come closer to having what is normally meant when speaking of the self-concept. Their concern with why they act makes them search for action meanings within their own personal histories and then express these meanings in the things that they do.

We want to emphasize that although personal agency level provides a summary depiction of an individual's competence with respect to action generally, this does not mean that effective performance is invariably associated with relatively high as opposed to low levels of action identification. As noted earlier, the optimal level of identification for effective performance depends on various criteria of the action's personal difficulty (e.g., Vallacher et al., 1989). When an act is personally unfamiliar or complex, for instance, thinking about the act solely in terms of its long-range consequences and implications is likely to hinder rather than facilitate its performance. In contexts where such acts are the rule rather than the exception (e.g., an emergency situation, learning a new skill, travel in a foreign country), then, advantage would be conferred on the person who undertook the 
acts with relatively low-level identities in mind. This is not to say, however, that a high-level agent would fail to identify such acts appropriately; presumably the high-level agent, like anyone else, would gravitate toward the level of identification required for effective performance. In characterizing the person's overall mastery of action generally, however, level of agency indicates the likelihood that a given act will be experienced as difficult or easy in the first place and hence how it is likely to be identified. On balance, because actions are generally easier for high- as opposed to low-level agents, the former can comfortably undertake a wider variety of actions with relatively high-level identities in mind.

It is interesting to consider the sorts of background factors that contribute to a person's level of personal agency. The present research was not designed with that goal in mind, of course, although it is worth noting that among the juvenile detainees, higher-level agents were more likely to have come from an intact family than were their lower-level counterparts. Perhaps a stable family environment provides a context in which children have the opportunity to develop skills, pursue hobbies, and otherwise achieve action competence, without the distractions and stresses of parental discord, change of residence, and the like. It remains for future research to confirm this lead and to illuminate other factors underlying the genesis of high versus low levels of personal agency.

\section{On the Nature of Personality}

Variants of the organizational scheme for action depicted here have appeared in a number of theoretical suggestions. Floyd Allport's (1937) teleonomic trends, Cantor and Kihlstrom's (1987) life tasks, Little's (1983) personal projects, Schank and Abelson's (1977) life themes, Heckhausen and Kuhl's (1985) intentions, Klinger's (1978) current concerns, Emmons's (in press) personal strivings, and our notion of ascriptive themes (Vallacher \& Wegner, 1985) all attempt to capture the individual's personal hierarchical organization of action. Rather than accumulating actions by semantic similarity into classes, these systems show the accretion of actions into meaningful themes through means-ends relations. Lower-level acts or means propagate upward to higher-level acts or ends because people do the ends by doing the means. Within such a system, the means need not resemble the ends in any way, and different means need not resemble one another. Semantic classification by resemblance is irrelevant.

Separate action groupings arise in such a system among the highest-level ends that individuals identify. The several content classes found among high-level action themes represent the individual's most general behavioral tendencies. They are not traits or dispositions, in the sense that the individual is inclined to perform frequently any rigid class of behaviors that are part of each grouping. Rather, they are classes of meaning that the person is prone to seek across the range of all behaviors. Many different lower-level actions, some seemingly irrelevant to each other and others seemingly in direct conflict, may still be seen by the individual at a particular time and place as promoting the same higher-level meaning.

The trait theorist might respond to these ideas by noting that they seem hopelessly idiographic, bound inextricably to the in- dividual's life and its unique unfolding over time. How can differences among individuals be understood when each individual assembles a unique set of action meanings? The partial solution we can propose at this time is contained in the dimension of levels of agency. Once it is recognized that acts vary widely in meaning, and that these variations render the traditional concept of trait as behavioral disposition quite intractable, the primary behavior-relevant trait left to be assessed nomothetically is level of agency.

The single trait of level of agency nonetheless appears to carry some of the explanatory weight usually assigned to all traits. In the continuing controversy regarding personal versus situational determinants of behavior (e.g., Mischel, 1968; Kenrick \& Funder, 1988), all traits are important; if individuals have traits, their behavior is taken to be personally determined, whereas if they do not, their behavior is seen as situationally caused. Personal agency, however, is a single trait that reflects all of personal versus situational causation at once.

This is because low-level agents' behavior tends to be under situational control, whereas high-level agents' behavior tends to be under the control of personal goals and self-conceived tendencies. Low-level agents are inclined to enter action contexts with little sense of the action's potential implications in mind, and so are primed to accept cues to higher-level meaning found in social feedback or situational pressures. In contrast, highlevel agents are better able to maintain their actions with respect to meaningful representations that they carry with them across times and settings. Without any concept of behavioral traits, therefore, the dimension of levels of personal agency still makes it fully possible to conceptualize the fundamental distinction between self and environment as sources of behavior causation. Because most people fall between the extremes on this dimension, it is not surprising that behavior for people in general can best be described as reflecting a combination of personal and situational influences.

\section{References}

Allport, F. (1937). Teleonomic description in the study of personality. Character and Personality, 5, 202-214.

Allport, G. W. (1966). Traits revisited. American Psychologist, 21, 110.

Andersen, S. M., \& Ross, L. (1984). Self-knowledge and social inference: I. The impact of cognitive/affective and behavioral data. Journal of Personality and Social Psychology, 46, 280-293.

Anscombe, G. E. M. (1957). Intention. Oxford: Blackwell.

Bem, D. J., \& Allen, A. (1974). On predicting some of the people some of the time: The search for cross-situational consistencies in behavior Psychological Review, 81, 506-520.

Bem, S. L. (1974). The measurement of psychological androgyny. Journal of Consulting and Clinical Psychology, 42, 155-162.

Bieri, J., Atkins, A. L., Briar, S., Leaman, R. L., Miller, H., \& Tripodi, T. (1966). Clinical and social judgment. New York: Wiley.

Broadbent, D. E., Cooper, P. F., Fitzgerald, P., \& Parkes, K. R. (1982). The Cognitive Failures Questionnaire (CFQ) and its correlates. British Journal of Clinical Psychology, 21, 1-16.

Buss, D. M., \& Craik, K. H. (1983). The act-frequency approach to personality. Psychological Review, 90, 105-126.

Campus, N. (1974). Transituational consistency as a dimension of personality. Journal of Personality and Social Psychology, 29, 593-600.

Cantor, N., \& Kihlstrom, J. (1987). Personality and social intelligence. Englewood Cliffs, NJ: Prentice-Hall. 
Cantor, N., \& Mischel, W. (1979). Prototypes in person perception. In L. Berkowitz (Ed.), Advances in experimental social psychology (Vol. 12, pp. 3-51). New York: Academic Press.

Colby, A., Kohlberg, L., Gibbs, J., Candee, D., Speicher-Dubin, G., Koffman, K., Hewer, A., \& Power, C. (1978). The measurement of moral judgment: A manual and its development. New York: Cambridge University Press.

Danto, A. (1963). What we can do. Journal of Philosophy, 40, 435-445.

Dishman, R. K., \& Ickes, W. J. (1981). Self-motivation and adherence to therapeutic exercise. Journal of Behavioral Medicine, 4, 421-435.

Emmons, R. A. (in press). The personal striving approach to personality. In L. A. Pervin (Ed.), Goal concepts in personality and social cognition. Hillsdale, NJ: Erlbaum.

Epstein, S. (1979). The stability of behavior: I. On predicting most of the people much of the time. Journal of Personality and Social Psychology, 37, 1097-1126.

Fenigstein, A., Scheier, M., \& Buss, A. (1975). Public and private selfconsciousness: Assessment and theory. Journal of Consulting and Clinical Psychology, 43, 522-527.

Fiedler, F. E., \& Chemers, M. M. (1984). Improving leadership effectiveness: The leader match concept (2nd ed.). New York: Wiley.

Goldman, A. I. (1970). A theory of human action. Princeton, NJ: Princeton University Press.

Heckhausen, H., \& Kuhl, J. (1985). From wishes to action: The dead ends and short cuts on the long way to action. In M. Frese \& J. Sabini (Eds.), Goal directed behavior: The concept of action in psychology (pp. 134-159). Hillsdale, NJ: Erlbaum.

Kelly, G. A. (1955). The psychology of personal constructs. New York: Norton.

Kenrick, D. T., \& Funder, D. C. (1988). Profiting from controversy: Lessons from the person-situation debate. American Psychologist, 43, 23-34.

Kipnis, D. (1971). Character structure and impulsiveness. New York: Academic Press.

Klinger, E. (1978). Modes of normal conscious flow. In K. S. Pope \& J. L. Singer (Eds.), The stream of consciousness: Scientific investigations into the flow of human experience (pp. 226-258). New York: Plenum Press.

Krantz, D. S., Glass, D. C., \& Snyder, M. L. (1974). Helplessness, stress level, and the coronary-prone behavior pattern. Journal of Experimental Social Psychology, 10, 284-300.

Little, B. R. (1983). Personal projects: A rationale and method for investigation. Environment and Behavior, 15, 273-309.

MacDonald, A. P., Jr. (1970). Revised scale for ambiguity tolerance: Reliability and validity. Psychological Reports, 26, 791-798.

Markus, H. (1977). Self-schemata and processing information about the self. Journal of Personality and Social Psychology, 35, 63-78.

Mischel, W. (1968). Personality and assessment. New York: Wiley.

Norman, D. A. (1981). Categorization of action slips. Psychological Review, 88, 1-15.

Otis, A. S. (1956). Self-administering tests of mental ability. New York: Harcourt Brace Jovanovich.

Pettigrew, T. F. (1958). The measurement and correlates of category width as a cognitive variable. Journal of Personality, 26, 532-544.

Reason, J., \& Mycielska, K. (1982). Absent-minded? The psychology of mental lapses and everyday errors. Englewood Cliffs, NJ: PrenticeHall.
Rokeach, M. (1960). The open and closed mind. New York: Basic Books. Rotter, J. B. (1966). Generalized expectancies for internal versus external control of reinforcement. Psychological Monographs, $80(1$, Whole No. 609).

Ryle, G. (1949). The concept of mind. London: Hutchinson.

Schank, R., \& Abelson, R. (1977). Scripts, plans, goals, and understanding. Hillsdale, NJ: Erlbaum.

Snyder, M. (1974). Self-monitoring of expressive behavior. Journal of Personality and Social Psychology, 30, 526-537.

Snyder, M., \& Campbell, B. H. (1982). Self-monitoring: The self in action. In J. Suls (Ed.), Psychological perspectives on the self(Vol. 1, pp. 185-207). Hillsdale, NJ: Erlbaum.

Thurstone, L. L. (1944). A factorial study of perception. [Psychometric Monograph No. 4]. Chicago: University of Chicago Press.

Vallacher, R. R. (1975). Dimensions of the self and situational self-consciousness in the perception of others. Unpublished doctoral dissertation, Michigan State University.

Vallacher, R. R., Bennett, J., \& Swann, W. B., Jr. (1982). [Self-certainty and its correlates]. Unpublished raw data.

Vallacher, R. R., \& Wegner, D. M. (1985). A theory of action identification. Hillsdale, NJ: Erlbaum.

Vallacher, R. R., \& Wegner, D. M. (1987). What do people think they're doing? Action identification and human behavior. Psychological Review, 94, 3-15.

Vallacher, R. R., Wegner, D. M., \& Frederick, J. (1981). [Experience and the identification of action]. Unpublished raw data.

Vallacher, R. R., Wegner, D. M., \& Frederick, J. (1987). The presentation of self through action identification. Social Cognition, 5, 301322.

Vallacher, R. R., Wegner, D. M., \& Somoza, M. P. (1989). That's easy for you to say: Action identification and speech fluency. Journal of Personality and Social Psychology, 56, 199-208.

Wegner, D. M., \& Vallacher, R. R. (1983). [Action identification level and maintenance indicator ratings]. Unpublished raw data.

Wegner, D. M., \& Vallacher, R. R. (1986). Action identification. In R. M. Sorrentino \& E. T. Higgins (Eds.), Handbook of motivation and cognition: Foundations of social behavior (pp. 550-582). New York: Guilford.

Wegner, D. M., Vallacher, R. R., \& Dizadji, D. (1989). Do alcoholics know what they're doing? Identifications of the act of drinking. Basic and Applied Social Psychology, 10, 197-210.

Wegner, D. M., Vallacher, R. R., Kiersted, G., \& Dizadji, D. (1986). Action identification in the emergence of social behavior. Social $\mathrm{Cog}$ nition, 4, 18-38.

Wegner, D. M., Vallacher, R. R., Macomber, G., Wood, R., \& Arps, K. (1984). The emergence of action. Journal of Personality and Social Psychology, 46, 269-279.

Witkin, H. A., Dyk, R. B., Faterson, H. B., Goodenough, D. R., \& Karp, S. A. (1962). Psychological differentiation. New York: Wiley.

Wittgenstein, L. (1953). Philosophical investigations. Oxford: Blackwell.

Wylie, R. C. (1979). The self-concept (Vol. 2). Lincoln: University of Nebraska Press.

Received March 1, 1988

Revision received February 21, 1989

Accepted February 22, 1989 